\title{
System Consequentialism
}

\author{
Avram Hiller
}

It should be indisputable that some forms of act-consequentialism can allow that actions have non-instrumental goodness/badness, which I shall call axiological valence. For example, an act-consequentialist may have a theory of the good according to which dancing is the only good and that acts are right insofar as they promote the greatest amount of dancing. Such a danceconsequentialist might at times be faced with a choice of how to act: should I now work to build a community center at which dancing will occur, or should I just dance? The former promotes the good since its consequence is the future existence of goods whereas the latter promotes the good because the act itself is a good; the right answer will turn on which of the two acts has the highest overall (expected ${ }^{1}$ ) dance-utility. For dance-consequentialism, dancing is not always the right action even though dancing is always a good. The axiological valence of the act itself is just one of the values in the calculus.

So it is possible to be an act-consequentialist and believe that some acts have axiological valence. ${ }^{2}$ All that an act-consequentialist must deny is that the rightness or wrongness of an act is independent of the value of the full range of the state or states of affairs that will ensue if the agent performs the act (relative to the values of the states of affairs that would be produced if the agent acts otherwise).

This paper gives reasons to believe that virtually all human acts are such that they have axiological valence. To conclusively prove that thesis would require a full theory of value; it is one thing to assume in a thought experiment that dancing has axiological valence but quite another to give adequate reasons why other human acts, both common and uncommon, are 
valenced. ${ }^{3}$ Thus the main goal of this paper is to set out the framework of an argument for the view that acts have axiological valence in the hope that the argument can be fleshed out more completely elsewhere.

The approach in this paper is somewhat circuitous. First, I argue against the view known as Mooreanism. Then I will show how this anti-Moorean argument may lead to a deep puzzle for consequentialism. Next, I respond to the puzzle by claiming that consequentialists should make use of an account of the value of systems; I call the resulting view system consequentialism. Then, I generalize the argument to show how it applies to most or all human acts.

The core assumptions used in the final step of the development of the view are taken from environmental ethics. There are two ways in which systems should play a role in consequentialist thinking. First, I assume, following Aldo Leopold (1980) and others, that systems on their own are valuable. Second, I claim that there are dependence relations between

humans and the environment. I assume, following Holmes Rolston (1994) and J. Baird Callicott (1989, 1999), that humans are parts of biotic (and other) systems. So in arguing for system consequentialism, I am attempting to bring system-based environmental thinking into a consequentialist framework.

\section{A counterexample to Mooreanism}

A common assumption in ethical theory is what is called Mooreanism, the view that the intrinsic value of an object or state of affairs supervenes on the object's or state of affairs' intrinsic properties. ${ }^{4}$ According to Moore, we should employ the isolation test, whereby the value of the thing is determined on the basis of its value when in isolation of everything else. 
The following is a counterexample to Mooreanism. Consider an athletic competition where an athlete has an opportunity to use a performance-enhancing substance in her training. Assume the following:

(1) There is no specific rule prohibiting that particular performance-enhancing drug, but it is clear that taking such a drug is against the spirit of the competition. (The drug can cause harm to one who ingests it, no other competitor is using it, and similar drugs have perpetually been frowned upon and subsequently banned.) (2) The way the drug works is that it makes training for the competition much easier; one who takes the drug will grow muscles much more quickly than one who doesn't take the drug. However, by the time of the start of the competition, there is no trace of the drug left in the athlete's body.

(3) The athlete's reason for competing is to enjoy the "thrill of victory," and not because of the prize money or other future consequences of the victory. I shall take it as a given that normally, the state of affairs of an athlete winning a competition (or, the pleasure or the prize an athlete gets upon winning a competition) has positive intrinsic value. However, if the athlete has taken a performance-enhancing drug to win the competition, the intrinsic value of the victory is less than if the athlete had not taken the drug - even if all the intrinsic properties of the competition are the same. By a commonsensical assumption, if the athlete uses the drug, the means used to achieve the victory are inappropriate and the victory itself thereby is not a good. If we imagine two possible worlds, in one of which the athlete trains diligently to win, and in the other, the athlete trains much less diligently but inappropriately uses a drug to achieve the same victory (i.e., one where the non-axiological intrinsic properties of the competition are the same), the victory in the former world is more of a 
good than the victory in the latter world. Because the intrinsic value of a victory is affected by what occurred prior to the victory, this is thus a counterexample to Mooreanism.

\section{The anti-Moorean puzzle for consequentialism}

Since the reason why the victory is not good seems to be that using the drug is an inappropriate way to train for the competition, the lesson of this example is that in certain cases, an end which is normally a good end may not be a good end if the means used to achieve the end are inappropriate. But if so, there is a deep puzzle for consequentialism. According to standard forms of consequentialism, the appropriateness of a means to an end depends only on the value of the end (relative to other available ends), and so the value of an end must be independent of any prior assessment of the appropriateness of the means. But this is precisely what one cannot do, if the anti-Moorean argument above is correct - the value of the end (the victory) depends on whether the means (taking the drug/training hard) are appropriate. If this is the case, then consequentialists' analysis of appropriateness is ungrounded. This is a significant puzzle for any standard consequentialist who agrees with the intuitions in the athlete case.

However, I'd like to argue that there is a way around the puzzle consistent with consequentialism. To see this, I suggest viewing the situation from the perspective of the athlete herself. How should she decide whether or not to use a drug? I propose as follows:

I want to win the competition, and taking the drug will help me do so. However:

(A1) [First-order axiological premise:] If I take the drug in order to win, it will undermine the goodness of the competition.

(A2) [Metaphysical premise about the relation between victories and competitions:] A victory in the competition is only intelligible in regard to the 
whole competition (i.e., victories don't stand apart, metaphysically, from the competitions in which they occur).

(A3) [Main axiological premise:] Since a victory in the competition is only intelligible in terms of the competition, if the goodness of the competition is undermined, the goodness of the victory is undermined.

(A4) Thus if I take the drug, the goodness of the victory will be undermined.

(A5) [Conclusion:] Since I only entered the competition to enjoy the goodness of the victory, I shouldn't take the drug since doing so would not allow for the victory to be any good.

This argument does not involve any prior analysis of whether the means to achieve the end are inappropriate, as the premises of the argument are phrased purely in axiological terms and not in terms of right and wrong. In this way, the consequentialist can solve the anti-Moorean puzzle. We don't need an antecedent account of appropriateness of means in order to determine whether an end is a good end; rather, we need an antecedent account of the value of the broader systems of which ends and means are parts.

However, this immediately puts the strain on (A1). My argument thus far does not establish much for the consequentialist, since it now requires us to account for why two possible competitions, rather than simply victories, can be better or worse even when their other intrinsic properties are the same. And it seems like a non-consequentialist will have a good explanation that is seemingly unavailable to the consequentialist: the competition is corrupted simply because, prior to the competition, the athlete acted inappropriately in training for the competition. Taking a drug to win a competition is unfair to the other athletes, and thus is wrong, and the wrongness of the act taints the whole competition. 
So the consequentialist needs to show that the reason why the competition itself gets corrupted is not because of the antecedent wrongness of taking the drug. However, such an account is indeed available. Consider the following modification of the case. Instead of the athlete facing a choice in taking the drug, let's assume that the she has unknowingly ingested the drug due to its accidental presence in some food she has eaten. Everything else about the case is the same: the athlete wins the competition due to the drug, and not because of exceptionally rigorous training. Had she not ingested the drug, she would not have won. But there is another possible world in which the athlete did not ingest the drug but did train much harder, and won the competition in an identical manner. It seems that the competition in that other possible world is a better competition than the competition in the given world.

This example exhibits the same properties as the original example even though the athlete has not done anything wrong; we should still regard the competition as tainted despite no wrongdoing. We do have an intuitive understanding of the goodness of competitions where the goodness of a competition varies in accord with its adherence to a principle of "may the best athlete win." ${ }^{, 5}$ Competitions which are won not by the best and best-trained athlete but by an athlete who ingests drugs are not as good as competitions where the winner wins by training hard. And this is the case regardless of whether the athlete intentionally takes drugs or not. My main claim is the following. As long as one can give an antecedent account of the value of systems, cases similar to those which inspire the anti-Moorean puzzle will not undermine consequentialism. In this way, consequentialists can account for intuitions that different means may lead to intrinsically identical ends (i.e., ends which have the same intrinsic non-axiological properties) which have different intrinsic value. 
What is a system? For the purposes of this paper, a system is defined as $a$ whole which has, as parts, interacting individuals which are tokens of types which have a necessary connection to each other. Two further refinements are needed. First, the generality of types must be restricted, since any two physical objects are tokens of the type physical object, and of course types are necessarily related to themselves. Second, the way in which the token individuals interact must be an instance of the necessary connection between the types and not merely an accidental connection. Admittedly, this definition of system is vague; more first-order theorizing, beyond the scope of this paper, must go into specifying the limits of the type-generality. Still, to give one illustration, consider the giant panda, a species which evolved to eat a certain kind of bamboo; bamboo composes 99\% of the panda's diet (Lumpkin and Seidensticker 2007). Furthermore, the panda has shaped the evolution of bamboo. Thus when the panda eats bamboo, there is a properly functioning system between them. A panda in confinement who gets sustenance from other types of food (say, from consuming trash left by people) may be said to lead a lesser life even if that food satisfies the panda's nutritional needs. ${ }^{6}$ I shall say more about systems below.

Above, I assume that the athlete wants to win the competition for the pure end of enjoying the victory. But what if, instead, the athlete has a goal of winning prize money to support a luxury vacation? Taking a performance-enhancing drug to win the prize money from a competition to promote that goal would still be wrong, of course, but there is a difference in the rationality behind it when compared to the original case. The idea above is that it is selfdefeating to take a drug to win a competition when one's goal is the pure enjoyment of victory. But there seems to be nothing self-defeating about using illicit means to earn money to go on a vacation. The best explanation of why this is so is that there is no necessary systemic connection 
between the end of going on a luxury vacation and the means of using a drug to win a competition. Thus the value of the vacation would not be compromised in the way that the value of the pure end of winning the competition is compromised were the athlete to use a drug to win. If this is correct, then it is not simply the inappropriateness of a means to an end which spoils the value of the end (as perhaps a deontologist would hold); rather, it is only when a means is inappropriate in a way relevant to a means-end system that the value of the end is spoiled. I take this as some evidence favoring the system-based view I advocate over a deontological explanation of the case.

The account given here concerning the axiological valence of actions is different from the example with which I began, that of dancing. In the original example, dancing is an act with intrinsic value. My claim in this section is that taking a drug has a different axiological valence than diligent training, but the differing axiological valences are not necessarily based on their intrinsic values. The difference in axiological valence is due to the way in which the two acts are parts of different systems which have different intrinsic values. The upshot is that a consequentialist may claim that one act is right and the other is wrong due not to any differences in the non-axiological properties of the future ends that the two acts produce but because of the way the acts themselves are relevant in determining the total value of the ensuing state of affairs. In that way, the athlete example is similar to the dancing example.

There are two prominent views which employ considerations similar to the ones just discussed. G. E. Moore famously believes in the principle of organic unities: the intrinsic value of a thing is not reducible to the sum of the intrinsic values of its parts. ${ }^{7}$ A Moorean may say that the value of the organic unity of the competition is less than the value of its parts when the competition is corrupted due to drug use. However, the view presented here is doubly anti- 
Moorean. First, as above, I reject the view known as Mooreanism about intrinsic value. But it also rejects the principle of organic unities. In these types of cases, the total value of the state of affairs can still be determined by adding the values of the components; it is merely that the components' intrinsic values are not determined purely on the basis of their intrinsic properties. This view has the benefit of preserving a highly intuitive principle of value-addition which Mooreans are forced to deny. It also preserves the intuition that the victory in the athlete case really is not a good. I will say more about organic unities below.

Another view which grapples with similar types of cases is particularism, as expressed by Jonathan Dancy. ${ }^{8}$ On Dancy's view, intrinsic value is non-Moorean and can vary depending on extrinsic factors. However, Dancy goes much further in claiming that all cases are like this. Although I do not wish to argue either for or against particularism here, it should suffice that the present view need not be committed to the bold thesis of particularism. It can, for example, still maintain that even though there is no general principle which indicates the intrinsic value of a victory when decontextualized, there are still general principles which determine the intrinsic value of victories when contextualized. We may still say, for example, that drug-fueled victories are not good even if we cannot say whether or not a victory, considered on its own, is good.

\section{Systemicism and system consequentialism}

In this section I shall provide an argument for the view that most or all cases of human action are similar to the case of the athletic competition in that the goodness of human ends depends (at least to some extent) upon the goodness of the broad system of which the end is a part. I shall call this claim the systemic dependency thesis, or systemicism for short. 
To see the reasons for holding systemicism, consider a generalized version of the reasoning which I above propose that the athlete employ:

(G1) I may wish to do action $A$ because $A$ is a way to produce end $E$ and $E$ is (normally) good.

(G2) However, doing $A$ to achieve $E$ corrupts system $S$.

(G3) $E$ depends essentially on $S$.

(G4) For any $x$ and $y$ where $x$ depends essentially on $y$, if $y$ is corrupted, so is $x$.

(G5) Thus (from (G3) and (G4)) if $S$ is corrupted, $E$ is corrupted, too.

(G6) Thus (from (G2) and (G5)) doing $A$ to achieve $E$ corrupts $E$.

(G7) Thus my reason for doing $A$ may be undermined, since the only reason I have for doing it is that it promotes $E$, which was supposed to be a good but in this case would be corrupted. In other words, when one has an end in mind and a means to promote the end, one should make sure that using such means don't create a corrupt system which undermines the reasons for pursuing the end in the first place.

The systemicist idea is that if one harms one's environment or other people to promote one's ends, one thereby undermines the proper connection one has to the environment or other people. Humans are necessarily dependent upon the environment and other people, and thus form a system. This dependency is not a mere physical dependency - people can physically live in isolation from others (although it is impossible for a human to live in complete isolation from air and food). Rather, given that people are evolved and embodied organisms, it is a necessary part of human nature we are connected to other people and to nature. So people's ends can only be understood as parts of that system.

Here is the formal argument for systemicism: 
(S1) [Metaphysical premise about human nature, instantiating (G3):] We are evolved, embodied, social beings essentially connected to other people and to the natural world. At least most if not all of our interactions with the natural world and with other people occur in the context of participating in a system. We, and a fortiori our ends, can only be understood as parts of the system.

(S2) [Main axiological premise, as in (G4):] When an end cannot be understood except as part of a larger system, and is essentially part of it, the goodness of the end depends on the goodness of the system.

(S3) [Premise about better and worse systems, as in (G2):] There are better and worse human/human and human/nature systems, depending on the ways humans use other humans or the natural world to promote ends. Some ways in which humans use other humans or nature corrupts the system between them.

(S4) Conclusion: There are better and worse human ends depending on the goodness of the systems of which the ends are parts.

If this reasoning is sound, then there will likely be pairs of actions whereby, even on actconsequentialist grounds, one is right and another is wrong even though the intrinsic, nonaxiological properties of the ends they produce are identical. It does not follow that the value of an end will always be negative if there is a problem with the system; I am only arguing for the weaker point that two ends which are parts of different systems may have different intrinsic values even if the ends are intrinsically identical.

The view which results from combining systemicism with a broad consequentialist framework I shall call system consequentialism. Like ordinary consequentialism, it is the view that an act is right insofar as the state of affairs that ensues from it is the best state of affairs. But 
the system consequentialist adds the proviso: the action itself may be part of a system whose value may depend on the nature of the action itself, and thus the utility of the end of the action is not independent of the action. Thus whether an action produces the best state of affairs cannot be determined independent of consideration of the nature of the action itself.

A second way in which system consequentialism differs from previous forms of consequentialism is that it accepts that ecosystems which are almost entirely independent of humans (and potentially even independent of all sentient beings) are valuable and thus are to be included in the calculus for determining right actions. However, I will not explore this facet of system consequentialism in this paper in detail, except to note that the systemicist view holds that systems have value, and thus it follows immediately that a system consequentialist agent should promote, or at least not reduce, systemic good, even for systems in which the agent is not a member.

\section{Holism in environmental ethics}

Although mainstream ethical theory has little or nothing to say about systems, my focus on systems is a familiar one within environmental ethics. Aldo Leopold (1980), Arne Naess (1989, 1995 [1973], and 1995 [1987]), Holmes Rolston (1994), J. Baird Callicott (1989, 1999), and Freya Mathews (1991), among others, argue for moral considerability of ecological systems or wholes, though they each have different conceptions of what a system is and different reasons for valuing systems. Despite the fact that the initial statement of Leopold's famous "Land Ethic" is seemingly made in consequentialist terms, ${ }^{9}$ within environmental ethics, the move from a traditional utilitarian perspective to a holist perspective has been accompanied by an abandonment of consequentialism more generally; none of the authors mentioned develop a 
holistic ethic in the context of consequentialist theory. One of the goals of this paper is to show that one need not abandon consequentialist normative theory while at the same time maintaining a holistic environmental ethical orientation.

Although my main goal for this paper is just to provide the framework of the systemicist argument and not to give a full defense of its premises, I should say some things to demonstrate their plausibility. A defense of premise (S1) would require a lengthy discussion of the metaphysics of personhood, and I do not wish to get bogged down in such an effort here. Rather than arguing for it directly, I'd like to suggest that the fact that is not generally accepted may be due to certain outdated aspects of the history of ethical theory. Utilitarianism originated at a time when metaphysical individualism - either in a Cartesian dualist or a Hobbesian materialist form - was prevalent. ${ }^{10}$ However, after Darwin, we now view humans as being non-accidentally connected to each other and, notably, to the non-human world. Indeed, the revolutions in environmental thinking over the last fifty years have led to a more holistic account of human nature and human ecology. ${ }^{11}$

The metaphysical view this paper presupposes is not nearly as extreme as a deep ecological view according to which humans are literally One with the rest of the world. ${ }^{12}$ Rather, the view here is just a denial of what is called Hume's Dictum, the view that there are no necessary connections between distinct existences. ${ }^{13}$ Contrary to the deep ecological framework, there are distinct individuals; yet, contrary to thoroughgoing individualism, there are essentiality conditions for individuals which depend on properties external to the individuals. ${ }^{14}$

Utilitarianism has been famously been said to suffer from a failure to respect the separateness of persons. ${ }^{15}$ In perhaps an ironic twist, my claim is that the problem with classical utilitarianism is not that it fails to respect the separateness of persons, but that it fails to respect 
the non-separateness of persons, for it operates with an outdated, overly individualist conception of the human person and the human good. One hope underlying this paper is that nonconsequentialists who believe that utilitarians have an overly simplistic conception of the good will be amenable to the systemicist account, and if so, will not be so tempted to reject consequentialism as a whole. As I note below, adding considerations of systems may help consequentialists respond to certain thought experiments which have long led people to prefer deontology.

My approach in supporting (S2) and (S3) is to point out that most cases of human activities are relevantly similar to the athletic competition. It is not obvious that they are. For one might argue that the only reason why an athletic competition has a telos is that people have given it one; and we have constructed the telos such that it may be undermined by competitors behaving in certain ways. However, for systems involving regular human actions, there is no constructed telos (and no non-constructed telos) and thus no general standards of better and worse systems.

The problem with this is that it leaves it mysterious why we create athletic competitions in the first place and instill them with a telos. There is a (normatively) good reason: we have athletic competitions because we have a larger conception of human good - a conception which includes human excellence and, for many competitions, teamwork and cooperation (Simon, 2003, Ch. 2). This is why we have a "may the best person/team win" view of competitions. Athletic competitions are simply instances of human interaction in which people work together (in a sense of togetherness which includes people functioning as adversarial competitors) to achieve broader human excellence. So, rather than the athletic example being a special case, or being a mere illustrative analogy, it is in fact an instance of the exact general phenomenon I am 
trying to argue for. One who accepts the intuitions above in the athlete case likely already

operates under a view of the human good which is represented by (S2) and (S3).

However, this admittedly is not a full defense of the teleology implicit in the systemicist metaphysics; one may wish to regard the conclusion of this paper as conditional upon (S2) and (S3). Nevertheless, upholding systemic value is common in environmental ethics - Rolston (1994) and McShane (2004) provide further defenses.

\section{Some examples of systemicism}

In this section I will give some examples which illustrate the systemicist view. First, it has been claimed that consequentialists cannot account for the full reasons for keeping a promise (Ross 1930, 34-35). It is supposed that the only reason under consequentialism why a person should keep a promise is if doing so has the best future consequences; that a person has made a promise provides no reason, in itself, for her to abide by it. One thing to note is that it seems that there will always be cases in which one ought to break a promise - for example, when maintaining a promise would lead someone to be unable to prevent something extremely bad from happening. Thus the issue of promising may be no more troubling for a standard consequentialist than for a deontologist. ${ }^{16}$ Although the standard consequentialist gives no respect for the sanctity of the promise, the deontologist on the other hand needs some principled ground to account for the cases when one ought to break one's promise.

However, the system consequentialist provides a middle ground position which shows why there is some negative axiological valence in breaking a promise while allowing that in some cases, the negative valence may be outweighed by some other good. When a person makes a promise to another, they create a system. If the promisor breaks the promise, the system 
becomes corrupted, and there is a loss in axiological valence. Even if the promise-breaker's ends are otherwise equal to the ends for which the promise is made, the fact that the ends are accomplished by a broken promise make the goodness of that end less than if the end were accomplished through maintaining a promise (or not having made a promise in the first place).

Another example is of a commercial product which is produced by slave labor. The enjoyment that a consumer gets from it is, on the present view, less of a good than the same level of enjoyment a consumer gets from an intrinsically identical item without the inappropriate origin. This is true even if the two consumers in question are fully unaware of the origins of the items. Some consumer items, such as wood products, are made from unsustainable treeharvesting practices which often involve clear-cutting forests. Other wood products are produced using more sustainable tree-farming practices which better respect the forest and the animals living in the forest. As with the slave labor example, the enjoyment that a consumer gets from a wood product from the former type of production is, on the present view, less of a good than the enjoyment a consumer gets from an intrinsically identical item whose origins are from the latter type of production. Again, this is true even if the two consumers in question are unaware of the origins of the items.

Many farm products are produced using methods of industrial agriculture which are very far removed from traditional means of food production and which serve to sever the close connection individuals once had to the sources of their food. On the present view, the enjoyment and nourishment a person gets from eating vegetables farmed seasonally in a local garden is a greater intrinsic good than the identical nourishment and enjoyment a person gets from eating mass-produced vegetables produced out of season and shipped across the world to the consumer. There are also concentrated animal feeding operations, or CAFOs. In a CAFO, animals are 
raised for slaughter in ways which cause tremendous suffering and fail to respect their natural tendencies. The systemicist claim is that the enjoyment a person gets from eating meat produced by a CAFO is less of a good than the enjoyment a person gets from eating otherwise identical meat which was killed through subsistence hunting. The latter is, arguably, a better system than the former.

These are just a few examples of how systemicism may be applied. In all of the examples, there are already good reasons not to support the worse practice - all else being equal, one should refrain from purchasing products whose production harms people, animals, or ecosystems. My point here is that systemicism gives a further reason why these types of products are to be avoided.

\section{Objections and replies}

To further explicate the system consequentialist view, I shall consider a number of objections and replies as follows.

O1. The systemicist account says that two qualitatively identical human experiences may have different values. But this is implausible.

R1. Many people already believe that there are goods outside of felt experience. Aristotle argues that how good one's life is can be affected by things that occur after death (Nicomachean Ethics: 1101b5-9). Robert Nozick's (1974: 42-45) experience machine example is also a famous (though controversial) argument for this point. One of the upshots of this paper is that these two points, which might easily be taken to be anti-consequentialist, are in fact consistent with consequentialism. 
O2. Claims about better and worse systems (such as those made in this paper) are ad hoc and are based more in subjective judgments made by contingently-placed individuals than upon any objective facts.

R2. It is true that the notion of a system used in this paper requires considerable further development. And it is also true that judgments about better and worse systems given above must be defended in much more detail than I have provided. However, the system consequentialist may make use of insights from environmental philosophers I mention above as well as ecologists, sociologists, and anthropologists, about the nature and value of systems.

O3. How broadly should we construe systems? An organic farm requires the sun, the solar system is part of the Milky Way, and so on. Do Earthly systems go all the way back to the Big Bang?

R3. There are many different levels of analysis of systems. While it is true, for example, that most every system on Earth depends on sunlight, and the sun is connected to the rest of the universe, etc., this is not a reductio of systemicism. We can appreciate the ways in which life on Earth is a small piece of the universe while at the same time still valuing Earthly systems. Also, given that we are at least at present unable to have significant effects outside our solar system, the value of the extra-solar world should have virtually no effect on the deliberative process. O4. How do we calculate the goods of systems in relation to the individual goods that are parts of the systems? In particular, we should not double count. That is to say that, in doing our utility calculations, we should not count both the good of an end as well as the good of the system of which the end is a part. ${ }^{17}$ But how else can we account for the good of both the system and of the individuals within the system? 
R4. A proper view of this issue demonstrates the benefit of the doubly anti-Moorean position in the paper, as this objection is more troublesome for a Moorean view. The Moorean has to answer first why an organic unity has the value that it has, contrary to an intuitive principle that the value of any combination of things is simply the sum of the values of the things. Second, since the Moorean must claim that it is the value of the organic unity and not the individual things within the unit that counts. But then in what way can the individual things be said to have value at all?

On the system consequentialist view, the value of any system is simply the sum of its parts. There is no concern that there will be double-counting; by counting the goodness of the system just once we are at the same time counting the goodness of its parts. But this is not to say that the value of the system is determined solely by analyzing the value of its parts; my argument has been that parts have the specific values that they have due in part to the roles they play in systems. The determination of the values of all the parts is simply made holistically with regard to the system.

O5. System consequentialism will lead to "environmental fascism." ${ }^{18}$ It will advocate sacrificing individuals for what it takes to be the greater good.

R5. First, I should note that objections of this sort are commonly made against consequentialism; the system consequentialist view is not unique in facing it. Furthermore, I should make clear that although this paper has emphasized the value of systems, it is still upholds the view that individuals have intrinsic value. In fact, it is consistent with there being a large plurality of values. To say that biotic systems are good does not entail that typical human pleasures are not good at all, even if they are caused by and part of an unnatural system. Since there are many different kinds of goods, ${ }^{19}$ the systemicist need not hold that that our current technologized lives 
are all-things-considered bad. And the system consequentialist will most likely reject actions which cause great harm to individual humans or to other sentient beings, since that would most likely cause a large amount of negative value. Furthermore, unlike Deep Ecology (Naess 1995 [1973]: 4), the systemicist is not committed to an egalitarianism among the values of all living things and systems.

\section{Conclusions}

There are four points I'd like to make in conclusion. First, system consequentialism is a rather hopeful and positive view to adopt. As I note above, Aristotle claims that our lives can be made better by events that occur after our deaths. He had in mind projects that succeed after the originator of the project has died. On the systemicist view, given that we are essentially connected to the natural world, the ways in which our lives can be made better after our deaths are many. Although there is a significant amount of environmental destruction that is taking place, there is still reason to believe that over the very long term, the natural world will continue to thrive at least in some ways. If systemicism is correct, this thriving means that our own quite limited lives are made better - much better - in virtue of being connected to the wider world..$^{20}$

Second, it should go without saying but systemicism runs quite contrary to ethical anthropocentrism. One of the main themes of this paper is that what is best for a person depends on the connection the person has to good systems external to the person. Anthropocentrism cannot be true on this account because one cannot make sense of the good of any individual without having some prior conception of the good of the environment in which the person lives and acts. If we are ethical egoists, we must thereby be environmentalists if systemicism is correct. $^{21}$ 
Third, system consequentialism may be used to resolve certain puzzles facing standard consequentialism. As I argue above, the system consequentialist may be able to account for the special obligation to maintain promises. More generally, system consequentialism may allow for a morally significant doing/allowing distinction. A human action which leads to an outcome is a different event than if the same outcome occurred without a human action, because a system in which one acts is different from a system in which one fails to act, even if the outcome is the same. Thus the appropriateness of the action may differ from the appropriateness of the inaction. More needs to be said to flesh this idea out, but it is a potentially promising path.

Fourth, system consequentialism may help resolve Derek Parfit's (1984: Part IV) repugnant conclusion, the claim that for any amount of highly satisfied, flourishing people, there is some larger number of barely worth-living lives which, together, would be better to have. The system consequentialist may claim that the kind of repugnant distribution of lives envisioned by Parfit would be a bad system. ${ }^{22}$

In sum, this paper has introduced a substantially new and promising normative theory, system consequentialism. The view accords with certain judgments within environmental ethics and can build upon the longstanding consequentialist tradition. Of course, much work remains to be done in explicating and defending the view; my hope for this paper has simply been to lay the groundwork for its development. ${ }^{23}$ 


\section{Works Cited}

Alrøe, Hugo Fjelsted and Erik Steen Kristensen. "Toward a Systemic Ethic: In Search of an Ethical Basis for Sustainability and Precaution," Environmental Ethics 25.1 (2003): 5978.

Aristotle. Nicomachean Ethics. Tr. Roger Crisp. Cambridge, UK: Cambridge University Press, 2000.

Attfield, Robin. The Ethics of the Global Environment. Edinburg and West LaFayette: Purdue University Press, 1999.

Callicott, J. Baird. In Defense of the Land Ethic: Essays in Environmental Philosophy. Albany, SUNY Press, 1989.

--- Beyond the Land Ethic: More Essays in Environmental Philosophy. Albany: SUNY Press, 1999.

Carter, Alan. "Towards a Multidimensional, Environmentalist Ethic." Environmental Values 20 (2011): 347-374.

Dancy, Jonathan. “Are There Organic Unities?” Ethics 113 (2003): 629-650.

Hiller, Avram. "Object-Dependence.” Essays in Philosophy 14.1 (2013): 33-55.

Hooker, Brad. "Consequentialism.” Oxford Companion to Philosophy, $2^{\text {nd }}$ edition.

Kagan, Shelly. “Rethinking Intrinsic Value.” The Journal of Ethics 2 (1998): 277-97.

Korsgaard, Christine. "Two Distinctions in Goodness.” The Philosophical Review 92.2 (1983): 169-195.

Leopold, Aldo. A Sand County Almanac. New York: Ballantine Books, 1980 [1949].

Lumpkin, Susan, and John Seidensticker. Giant Pandas. New York: HarperCollins, 2007. 
Mathews, Freya. The Ecological Self. London: Routledge, 1991.

McShane, Katie. "Ecosystem Health” Environmental Ethics 26 (2004): 227-245.

Moore, G.E. Principia Ethica. Cambridge, UK: Cambridge University Press, 1959 [1903].

Naess, Arne. Ecology, Community and Lifestyle: Outline of an Ecosophy. Tr. David Rothenberg, Cambridge University Press, 1989.

--- . "The Shallow and the Deep, Long-Range Ecology Movement: A Summary." The Deep Ecology Movement: An Introductory Anthology. Eds. Alan Drengson and Yuichi Inoue. Berkeley: North Atlantic Books, 1995 [1973]. 3-9.

--- . "Self-Realization: An Ecological Approach to Being in the World." The Deep Ecology Movement: An Introductory Anthology. Eds. Alan Drengson and Yuichi Inoue. Berkeley: North Atlantic Books, 1995 [1987]. 13-30

Norcross, Alastair. "Two Dogmas of Deontology: Aggregation, Rights, and the Separateness of Persons." Social Philosophy and Policy 26.1 (2009): 76-95.

Nozick, Robert. Anarchy, State, and Utopia. New York: Basic Books, 1974.

Pettit, Philip. "The Consequentialist Perspective." Three Methods of Ethics. Eds. Marcia Baron, Philip Pettit, and Michael Slote. Malden, MA: Blackwell, 1997. 92-174.

Rawls, John. A Theory of Justice. Cambridge, MA: Harvard University Press, 1971.

Regan, Tom. The Case for Animal Rights. Berkeley: University of California Press, 1983.

Rolston, Holmes. "Environmental Ethics: Values in and Duties to the Natural World." Reflecting on Nature: Readings in Environmental Philosophy. Eds. Lori Gruen and Dale Jamieson. New York: Oxford University Press, 1994. 65-84.

Ross, W. D. The Right and the Good. Oxford: Clarendon Press, 1930. 
Schweitzer, Albert. "Reverence for Life." Environmental Ethics, $5^{\text {th }}$ edition. Eds. Pojman and Pojman. Belmont: Cengage, 2008 [1923]. 131-138.

Simon, Robert. Fair Play: The Ethics of Sport. $2^{\text {nd }}$ edition. Boulder, CO: Westview Press, 2003.

Williams, Bernard. "A Critique of Utilitarianism." Utilitarianism: For and Against. Eds. J.J.C. Smart and Bernard Williams. Cambridge, UK: Cambridge University Press, 1973: 77-150.

Wilson, Jessica. "What is Hume's Dictum, and Why Believe It?" Philosophy and Phenomenological Research 80.3 (2010): 595-637. 
${ }^{1}$ In this paper, I do not take a position as to whether consequentialists should focus on expected utility or actual utility. Additionally, I will often omit the "act-" prefix from "actconsequentialism;" still, all instances of "consequentialism" in this paper denote actconsequentialism. Furthermore, I will only consider an agent-neutral, maximizing form of consequentialism. However, those who accept alternative forms of consequentialism may still accept the argument in this paper.

${ }^{2}$ Bernard Williams makes this point in (1973: 84-85).

${ }^{3}$ See Hooker (2005) for this concern about consequentialist views which accept that acts have axiological valence.

${ }^{4}$ See G.E. Moore (1959: Ch. 1). I should note that here, and throughout the paper, I use the notion of intrinsic value in the way that Christine Korsgaard (1983) uses the notion of final value - value as an end. If intrinsic value simply meant value which is (locally) supervenient on intrinsic properties, then Mooreanism would be true by definition and would not be a substantive view. I should also note that Shelly Kagan (1998) argues against Mooreanism. For reasons I outside the scope of this paper, I reject most of Kagan's examples. Nevertheless, even if they do work, they do not have the substantive ramifications that my own example has.

${ }^{5}$ See Robert Simon (2003: Ch. 2) for a similar account.

${ }^{6}$ See Mathews (1991: 124) for a similar point.

${ }^{7}$ See Moore (1959), pp. 27-31.

${ }^{8}$ For discussion relevant to theses points, see Dancy (2003). 
9 "A thing is right when it tends to preserve the integrity, stability, and beauty of the biotic community. It is wrong when it tends otherwise" Leopold (1980: 262).

10 There is a long tradition in environmental ethics to specifically reject the Cartesian approach of placing what is essential to a person outside the natural environment; to my knowledge Schweitzer (2008 [1923]) was the first.

${ }^{11}$ See Mathews (1991: Ch. 1) for a deeper analysis of the history of individualism, though I do not accept all aspects of her account.

${ }^{12}$ See Naess (1989) and Alrøe and Kristensen (2003).

${ }^{13}$ See Wilson (2010). However, Wilson adds a restriction on the definition of Hume's Dictum, such that it only applies to what she calls "intrinsically-typed" objects. Whether the metaphysical view of persons espoused in (S1) violates the letter of Hume's Dictum is not of import here; what matters is the metaphysics.

${ }^{14} \mathrm{I}$ argue for this metaphysical position in more detail in Hiller (2013).

15 As argued by Rawls (1971), 27. However, I am sympathetic with Alastair Norcross's (2008) rejection of the "separateness of persons" argument.

${ }^{16}$ A similar point is made in defense of consequentialism in Pettit (1997: 152).

${ }^{17}$ See Robin Attfield (1999: 40) for this concern.

18 Tom Regan (Regan 1983: 361-362) makes this objection against Leopold's land ethic.

${ }^{19}$ See Carter (this volume and 2011) for a defense of a multidimensional axiology which differs from the present view but which could be used in defense of systemicism from the charge of environmental fascism.

20 The view in this paragraph is analogous to that in Naess (1995 [1987]: 25-28).

21 This too is shared with the deep ecological view as in Naess (1995 [1987]). 
${ }^{22}$ See Carter, this volume, for a somewhat related solution to the repugnant conclusion.

${ }^{23}$ Earlier versions of this paper were presented at Lewis and Clark College, the 2010 Rocky Mountain Ethics Congress, and the 2009 Inland Northwest Philosophy Conference, and I wish to thank audiences on all three occasions. Thanks also to Ramona Ilea for helpful comments on an earlier draft. 